\title{
Polishing the rough edges: A copyeditor's perspective
}

\author{
Melody Schwantes ${ }^{1 *}$ \\ 1 Appalachian State University in Boone, NC, USA \\ *melodyschwantes@gmail.com
}

Published: 1 March 2018

It is the rare occasion for the copyeditor to be asked to pen an editorial for a publication, much less a peer-reviewed journal. However, as is the ethos of Voices, many positions and ideas are respected and nurtured-even the copyeditor's. Editing is a job I rather fell into in many ways. Being one of the few native English speakers in my doctoral program at Aalborg University in Denmark, I was looking for a way to give back to the community of scholars who supported me through my studies. Truthfully, I think I felt guilty writing my dissertation in my native tongue when my cohort had to struggle through the challenges of writing in the dominant scientific language of English. Editing their work for English language corrections was one way I could do that. Somehow in that editing space I began as an article reviewer for Voices, then moved to the editorial board, and now I'm happily in my role as copyeditor. Since coming into this position with the Voices team, I have had the distinct position of reading every article accepted for publication with a fine-toothed comb.

Some might assume that copyediting would be a tedious, boring aspect of publishing, but my experience has been more akin to polishing up any rough edges that exist with language or fixing any APA style issues. Clearly there is quite a bit of nitpicking involved, however, the contributors to Voices present such thoughtful, meaningful, work that most of the time I am grateful to read each and every article. Some of them may not have been the type of article that I would have purposefully sought out, but oftentimes, those are the ones that have left the greatest impression on me.

On many occasions, in the middle of copyediting, I become so engrossed in what the authors are addressing that I have to start over completely. I have to remind my brain to keep an eye out for comma splices, obscure APA style mandates, and my personal favorite, the Oxford comma. The articles in this edition are no different. What strikes me as a similarity in these articles is the relationships that are discussed. The authors encourage a dialogic approach whether it is between therapist and client (e.g., Fairchild \& Mraz; Silverman; Coombes) or between therapist and other professionals (Gross; Pearson). These reflexive exchanges deeply honor the sacred work that happens with the co-creation of music together.

To begin, Coombes presents her work with asylum seeking families in Wales. She positions her article in respect of the impact that work has had on her. She states, "For myself, 3 years later, I still find it hard to shake the feelings of disorientation and of being off-balance that this work evoked. What was striking at the time, and remains so, is that some level of a commonality of experience between the group and myself emerged. Being lost, not knowing where to go; these moments were powerful and have now woven themselves into my world-view and inform my work with this client group." 
In Fairchild and Mraz, the therapist (Fairchild) and an 11-year old young person (Mraz) discuss the impact that music therapy sessions had on each of them. In this rare, public dialogue between therapist and client, we catch a glimpse of the power of the exchange that occurred in their collaboration. They also give us further insight into their work by providing a link to a recording they created during their time together, which I would encourage everyone to spend time listening to.

Vaillancourt, Da Costa, Han, and Lipski present their research with an intergenerational singing group in a community based setting. This project is particularly intriguing given that the singing group is intergenerational and the researchers are intergenerational. The authors discuss their collaboration with each other and with their participants.

Another group of researchers spanning four different countries and cultures, McCaffrey, Carr, Solli, and Hense offer a collective presentation of their individual work in mental health recovery. They provide examples from their doctoral research to buoy the recovery oriented theoretical perspective and challenge music therapists to consider employing this approach and move away from the more dominant medical model. Their hope is to create more dialogue and discussion among music therapists working with service users in mental health recovery.

Silverman also discusses the importance of dialogue between therapists and clients in his investigation of the Coping-Infused Dialogue through Patient-Preferred Live Music Protocol (CID-PPLM). Dialogue is represented on two levels in this article; between music therapist and service users and then between Silverman and the music therapists using the CID-PPLM. Here we see thoughtful consideration of using frameworks for addressing coping and stressors for adult medical patients.

Gooding provides us with a review of Wheeler and Murphy's (2016) book, An Introduction to Music Therapy Research. She recommends this text to beginning researchers and students and discusses its potential integration and usefulness across the music therapy curriculum. Even in Gooding's book review, we see the expression of the relationships that are formed in music therapy. In this case, it is the relationship between educator and student.

Gross brings us a reflection of the social model of disability and its applicability to the field of music therapy. As language is a huge part of the copyediting process, Gross' explicit description and the use of "disabled people" I found to be quite helpful and straightforward. His presentation of the social model of disability is thoughtful. He adeptly incorporates all of the articles that were presented in a special edition of Voices (2014, vol. 3) and in many ways engages with the various authors of that edition through their text.

Finally, Pearson asks us to step back and engage with those who may use the term music therapy differently than we do. She argues that it provides us the possibility of refining our work. In her conclusion she challenges us by stating, "Yet taking this interdisciplinary leadership role as health-musicking experts is one way of raising awareness of the profession. And remembering that each inaccurate use of the term 'music therapy' is also, usually, a great compliment to the power of music, and a sign that the culture of care is well on its way to fully embracing the valuable service we offer."

As you peruse the articles in this edition, I hope that you will take a moment to consider the gift that all of these authors have given. Crafting the words to explain the often-ineffable experience of creating music together with others within the therapeutic milieu is no easy task- not to mention the added challenge for non-native English writers. As I polish up the words and commas for each edition, I am continually reminded of that challenge and grateful for each opportunity to allow the writers voices to shine through just a little more. 